International Research Journal of Management, IT \& Social Sciences
Available online at https://sloap.org/journals/index.php/irjmis/
Vol. 6 No. 6, November 2019, pages: 104 110
ISSN: 2395-7492
https://doi.org/10.21744/irjmis.v6n6.783

\title{
Multidimensional Diagnosis of Competitive Anxiety in Youth
} Baseball Team

Received: 27 June 2019

Accepted: 30 September 2019

Published: 28 October 2019

competitive anxiety;

multidimensional;
Milan Ochoa Chang a

Ana Celia Matarán Torres ${ }^{b}$

\section{Keywords:}

baseball;

diagnosis;

psychological;

Article history:

psychological;

\begin{abstract}
Santiago de Cuba It is one of the provinces with the best sports results in Cuban history, baseball is one of the leading disciplines in this regard, however, in recent years, such achievements have been affected. Multiple are the answers that technicians, researchers, and specialists have tried to offer these unfortunate events. Youth baseball has not been exempt from this problem and, in this sense, Sports Psychology has played an important role in the study and search for scientific alternatives that contribute to reversing these results. During the last 3 years, high manifestations of competitive anxiety have been observed in baseball players in this category, this fact motivates the present investigation, it aims to rigorously diagnose how this negative emotion has been presented in said population. To complete the objective, the 25 members of the Santiago youth team were selected as a sample, the study is descriptive, being able to record, analyze and describe the general and observable characteristics of anxiety in real moments of training sessions and competitions, it is supported by the qualitative-quantitative methodology using psychological techniques such as observation, interview, CSAI-2, attitude tests for competition and appreciation of time and pulsometer. In the evaluation carried out it was evidenced that there is a high incidence of competitive anxiety reflected through cognitive, physiological and behavioral manifestations which impose the future challenge of regulating such behaviors that allow improving the competitive result.
\end{abstract}

2395-7492@ Copyright 2019. The Author. This is an open-access article under the CC BY-SA license (https://creativecommons.org/licenses/by-sa/4.0/) All rights reserved.

\section{Author correspondence: \\ Milan Ochoa Chang, \\ Universidad de Oriente, Santiago de Cuba, Cuba. \\ Email address: milan.ochoa@nauta.cu}

\section{Introduction}

Anxiety is the emotional response that human beings experience in situations that are perceived as dangerous or worrisome, it constitutes a mechanism to react better in difficult times. However, when a person is frequently anxious,

\footnotetext{
${ }^{a}$ Universidad de Oriente, Santiago de Cuba, Cuba

${ }^{\mathrm{b}}$ Universidad de Oriente, Santiago de Cuba, Cuba
} 
without a possible reason for doing so, then anxiety becomes a problem producing unpleasant sensations for the individual. Understanding anxiety as a normal reaction, the goal is not to make it disappear but to learn to regulate it and reduce it to manageable and adaptive levels (Singh \& Parmar, 2015; Sjaifullah, 2019).

During sports activity, anxiety can be generated in the presence of positive or negative situations that could result in success or defeat, both of which cause changes in the subject that force him to mobilize his adaptive and balancing processes; although, like other situations in life, aversive experiences generate more anxiety. The anxiety in a sport activity is particularly wide due to the fact that here the person has a considerable background of physical and neuropsychic load in training and competition sessions, being constantly subjected to the performance of the most varied interpersonal and environmental influences (Jodra, 2002). This author continues explaining that, regardless of the positive or negative sense that a given stimulus may have, there are some characteristic situations that contribute to converting a stimulus into an anxiety generator; Among them we have: changes in the usual situation, insufficient or erroneous information, overload in the processing channels, importance of the event, uncertainty, imminence of the stimulus, lack of ability to control the situation, duration of the situation, trait anxiety and the self-esteem.

A high degree of anxiety has been considered as an interfering element on sports performance, although it is necessary that it exists at an adequate level. It is considered that a high state of anxiety can cause reactions such as fear, anger, irritability, worry or guilt (Williams, 1991); this state is identified with a series of physical and psychological symptoms, among which would be:

a) Physiological symptoms, such as the acceleration of the heart rate, increased blood pressure, increased muscle tension, breathing difficulties, sweating, and dryness in the mouth.

b) Psychological symptoms in the moments before the competition, where mistrust, negative thoughts, inflexibility, worry, attention difficulties, accentuation of personal conflicts, decrease in information processing capacity, problems in decision making arise.

c) Psychological symptoms before and during the competition, where alterations in thinking appear (such as doubting the effectiveness of training or the ability of athletes), decreased self-control, fatigue, insomnia, irritability, distraction.

In Cuba, anxiety has been studied at the point of departure of the whole multidimensional approach, however, one of the contributions taken as a reference in this work results from the complexity of the phenomenon and its multidimensional character and the power to emphasize that the instruments of The evaluations used are, despite their number, partial in terms of distinguishing all the attributes of anxiety and sometimes do not allow inferences of a clear practical utility (Garcia, 2001). This topic is complex and in line with the new advances in the theory of emotions.

The symptomatology described above generates negative effects on sports performance, especially on decisionmaking capacity, whose influence is decisive in an activity where action alternatives must be decided in a short time. The situation of competitive anxiety can affect the athlete perceive the moment of the competition as something threatening, which is manifested in cognitive, physiological and motor responses that can be evaluated and analyzed.

Various studies refer in particular to anxiety in sport, its causes, influences and consequences for sports performance, the most recent research is oriented towards the development of broader theoretical definitions of anxiety and in the identification of the determining factors of its development, a large group of researchers also develop questionnaires or anxiety scales specifically for sport, considering them to be better predictors of behavior and manifestations of anxiety in this area and in correlation there is a tireless work to establish more effective strategies for anxiety management in sports. In Cuba, studies published in this regard are still insufficient. Some authors conducted descriptive and interventive investigations of different manifestations of anxiety state in Cuban athletes (Garcia, 2001; Ordeñez, 2003; Milanés, 2015; Oliva \& Ochoa, 2016). In most of the mentioned studies, the approach to the adolescent sports population is scarce, that is why it is essential to deepen the particularities of this stage due to the specific conditions of development that are presented in this stage and because of the importance of the preparation of athletes from an early age towards a stage of excellence and maturity Baseball is considered the national sport in Cuba. It is the activity of greater roots and tradition of the Cuban people that has shown innumerable sporting events endowed with achievements and feats despite the difficulties and barriers that have had to be faced after the revolutionary triumph. An upward concern has warned all personnel involved in the development of this sport in the country, no effort is spared to solve all the problems detected through scientific and specialized studies, so it is worth highlighting some research conducted from different perspectives in different branches of science:

a) Tackling technical tactical aspects (Wanton \& Sánchez, 2013; Hernández, 2015; Ortega, 2016; Ríos, Sánchez, and Rojas, 2019)

Chang, M. O., \& Torres, A. C. M. (2019). Multidimensional diagnosis of competitive anxiety in youth baseball team. International Research Journal of Management, IT and Social Sciences, 6(6), 104-110. https://doi.org/10.21744/irjmis.v6n6.783 
b) Biomechanical and anthropometric analysis (Fabra, 2015; Rodríguez, 2016; Guzmán \& Pereiro, 2018; Quintana, 2019; Mesa, Pipper \& Ferie, 2018)

c) Formation of values, history, and identity (Váldes, 2008; Lazo, Taboada and Casero, 2013)

In the sciences applied to sport, Psychology is one of the most protagonists in this regard, in this area have been investigated, such:

a) Agents and psycho group (Casals \& Yumar Lage, 2014; Hidalgo \& Naranjo, 2016; Galvez \& Qui ones, 2018; García, 2019)

b) Aspects of psychological preparation (Gonzalez \& Padilla, 2007; Menéndez \& Estua, 2013)

c) Cognitive and emotional processes (Compta \& Naples, 2015; Cisneros, 2016; Suárez, 2016)

Regarding this topic it is appropriate to point out that in the Comprehensive Program of Baseball Athlete Preparation in Cuba (2016-2010) it is not addressed, with the relevance that it deserves, the psychological preparation for competitive situations, taking into account, and only in a very superficial way, the motivational aspect, so that new contributions are imposed that give a preponderant place to this axis transversal of the preparation of the athlete. Despite this, the National Institute of Sports and Recreation, in its corporate purpose (Objective 3, Key Results Area 3, Indicator 2, Teaching, Science and Technology, 2017) emphasizes the need to apply Science, Technology and Innovation in the substantive processes of Cuban sport, Sports Psychology being one of the greatest architects of development achieved to date with the evolution of revolutionary sport. This particular acquire news in the intervention of the director of the Center for Research on Cuban Sports, Dr. René Romero, on the occasion of his participation in the round table "The Cuban sports movement" held on January 2019.

Santiago de Cuba, province that includes among its social successes, the vertiginous development of various sports disciplines are rooted in the baseball tradition par excellence; its people have incorporated, since the practice of this sport was annexed at the end of the 19th century and later driven by the triumph of the Cuban revolution, the passion for baseball. The public from Santiago is one of the most demanding in the country, enjoying the successes with fierceness but also suffering inconsolably the failures. In the province of Santiago, Baseball has found, in recent times, a decline in its results despite the efforts made by coaches, technicians, specialists, and local authorities, which calls for the analysis of those parameters that negatively affect the Physical, technical-tactical and psychological preparation of baseball athletes.

The experience of psychological work with the youth baseball category has allowed, through factual diagnosis, to detect inadequacies with the presence of high levels of anxiety in competitive contexts shown through cognitive, physiological and behavioral manifestations such as excessive sweating, gastric disorders, increased heart and respiratory rate, widespread presence of negative thoughts, excessive worry and loss of concentration, as well as distortion of the technique and hurried acts when throwing and batting.

In correspondence with these insufficiencies, this work aims to make a detailed diagnosis of the most frequent manifestations of competitive anxiety as well as the detection of possible causes that condition it. This study will characterize the behavior of the cognitive, physiological and behavioral indicators at the starting point of developing in immediate projects psychological intervention strategies to favor the regulation of these negative emotional states and improve, in the end, the team's sporting result.

\section{Materials and Methods}

The present study is descriptive, being able to record, analyze and describe the general and observable characteristics of anxiety in real moments of training sessions and competitions, this presupposes the natural framework (on the playing field) in the investigation is taking place.

The methodology used is qualitative and quantitative according to the use of tools for obtaining and managing information with the competition of statisticians to arrive at more accurate conclusions, allowing the analysis and interpretation of the naturalness in which competitive anxiety is expressed in the real conditions of the pitch

The sample is made up of twenty-five baseball players that make up the youth baseball team participating in the competitions, this is selected using the non-probabilistic and intentional criteria, observing characteristics that particularize it within the population in which the research is conducted. The average age is 16.3 years, they have a sporting age that averages 9, 28 years. In the baseball team, they occupy different positions, within which we have nine pitchers, two receivers, two first bases, two-second bases, two short fields, two-third bases, and six gardeners. 
The research is helped by theoretical methods such as synthetic analytical and deductive inductive, also uses empirical methods such as participant structured observation and interview. In addition, psychometric tests such as the Questionnaire of Anxiety States (CSAI-2) and Attitude for competition (APC) are used, as well as field tests (pulsometer and time appreciation test).

In this diagnostic evaluation the application of the structured observation participant to various training sessions and competitive stops in order to obtain elements that characterize the anxiety in athletes of the youth baseball team of the Santiago town and establish possible differences in these very different areas (training and competition). The indicators taken into account are distributed and operationalized, respectively, in the cognitive order (worry, constant fear, lack of control over one's thoughts, feelings of threat or danger, difficulty concentrating, decision-making problems, negative expectations, feeling of confusion and increased doubts), behavioral (agitation and balancing of legs and arms, nervousness, tiredness, alertness or hypervigilance, clumsy and disorganized movements) and physiological (digestive discomfort - epigastric jump, stomach knot, diarrhea, onychophagy, tension muscle, vertigo or feeling faint, shortness of breath or hyperventilation, tingling)

The diagnosis is complemented by interviews with the members of the youth baseball team with the aim of knowing how these are perceived in stressful situations such as competition, what thoughts and behaviors they are characterized by emphasizing cognitive indicators or, behavioral and physiological and, in this way, corroborate the observed manifestations.

On the other hand, the State of Anxiety Questionnaire (CSAI-2) and the Attitude for Competition test are applied, the first of which aims to perceive anxious behaviors in the group of athletes studied and the second investigates the presence of positive attitudes or negative of the same towards the competitive moments.

Simultaneously the diagnosis is complemented with field tests to each of the players of the youth team, in this case the pulsometer and the time appreciation test are used; The first test aims to record physiological reactions such as heart rhythm in seemingly normal situations such as training and under stress-enhancing conditions such as competition. For their part, measurements are made to baseball players related to the perception of time to determine individual regularities linked to cognitive processes such as attention, a category that constitutes an element that can be modified before certain anxious manifestations.

*Anxiety States Questionnaire (CSAI-2): this one of the most important tests for Sports Psychology, was created in 1990 by Rainer Martens with the purpose of investigating and evidencing the effects of anxiety on the performance of the athletes. This instrument is made up of twenty-seven items that measure cognitive anxiety, somatic anxiety, and self-confidence, being the most used version for the multidimensional measurement of anxiety.

** Attitude for competition (APC): this scale was prepared in 1977 by Janin and is intended to perform an operational diagnosis on the attitude of athletes with respect to upcoming competitions in different sports, this test allowed to predict possible negative or positive states of the members of the youth baseball team in those circumstances.

As a mathematics statistical method, descriptive statistics are used for which the percentage calculation is used, this allows the information to be processed from the results of instruments applied in the diagnosis, in addition to ensuring an optimal approach in qualitative assessment. The processing is based on the SPSS 19 statistical package.

\section{Results and Discussions}

\section{Participant observation}

In the analysis of the resulting data, it can be determined in the physiological indicator that, during training sessions, they are practically absent in large part of youth baseball players tingling sensations (92\%), shortness of breath or hyperventilation (80\%), vertigo (84\%), muscle tension (52\%), as well as onychophagy and digestive discomfort (60\%). A very different situation is observed during the development of stops and competitions, although, in the case of vertigo (72\%) and tingling (60\%), a very low incidence continues to be shown. However, the moderate presence (44\%) of digestive discomfort and onychophagy (40\%) are detected in indices to be considered, as well as the existence, to a slight extent, of muscle tension and lack of air or hyperventilation, both with an incidence of $52 \%$.

Related to the cognitive indicator is detected, as reflected in the analysis of the physiological indicator, there are visible differences between what is detected in the competitive field and training. It is recognized that worry and constant fear (80\%), lack of control of one's thoughts $(72 \%)$, the feeling of threat or danger (92\%), difficulties in concentrating $(72 \%)$ and making decisions $(60 \%)$, as well as negative expectations $(60 \%)$ and the feeling of confusion

Chang, M. O., \& Torres, A. C. M. (2019). Multidimensional diagnosis of competitive anxiety in youth baseball team. International Research Journal of Management, IT and Social Sciences, 6(6), 104-110. https://doi.org/10.21744/irjmis.v6n6.783 
and increased doubts (92\%) are practically absent in large part of youth baseball players during training sessions. In contrast, for competitive activity, the majority of cognitive manifestations in the members of the youth baseball team vary in their incidence tending to increase. Thus, for example, concern (36\%) and difficulty concentrating (48\%) observe a moderate presence. Somehow you also perceive the constant fear (44\%), the lack of control of one's thoughts $(32 \%)$, the difficulty in making decisions and the feeling of confusion and increased doubts $(52 \%)$.

Considering the behavioral indicator, it is observed that the manifestations of nervousness, tiredness, hypervigilance, and disorganized movements occur practically zero in $84 \%, 64 \%, 96 \%$, and $64 \%$, respectively. However, during the development of competencies, these expressions are visibly modified. Such is the case of nervousness and disorganized movements, both reflected in $60 \%$ of athletes on the most pronounced evaluation scale (very much), these indexes show alarming difficulties, especially because in team sports indicators such as these hinder actions collectively and consequently affect the competitive outcome. Similarly, it is reflected that $48 \%$ of the population studied shows a moderate incidence of signs of fatigue, an element that can point, regardless of its underlying anxiety component, towards the unequal distribution of training loads and also the intensity and prolonged extension of the competitive period.

\section{Interview with youth baseball players}

Through the analysis of what was expressed by baseball players, it is perceived that all of them refer to experiencing various manifestations of anxiety in the cognitive, behavioral and physiological order during the development of any competition, not happening in the same way in the training. Athletes describe thirteen ways in which they manifest states of competitive anxiety, of which the ones belonging to the physiological indicator are the most representative such as increased heart rate (96\%), onychophagy (92\%) and sweating of the hands (84\%). On the other hand, the cognitive indicator reflects as main exponents the constant worry $(92 \%)$ and the negative thoughts $(84 \%)$. In the case of the behavioral indicator, the occurrence of technical tactical errors represented in $88 \%$ of athletes is highlighted. In this regard, it is worth noting that only $36 \%$ referred to some ways to regulate or control these manifestations, within which they indicated: "breathing deeply", "putting a positive mind" and "requesting help from the psychologist"; This shows that most athletes lack tools to deal with situations like those described above.

From another perspective, some members of the youth baseball team expressed that on several occasions they have this type of behavior for feeling pressured, either because of the growing expectations of the family, for achieving social recognition and for inadequate management of the coaches (presence of criticism not constructive during competitions, inadequate correction of tactical errors).

\section{Anxiety State Questionnaire (CSAI-2)}

In the case of the three indicators evaluated, alarming values are presented, cognitive anxiety and self-confidence show identical and very high values, this translates into twenty-one athletes $(84 \%)$ have indices of Moderate to very anxious behavior, although the balance leans slightly towards the last rating scale (eleven athletes for 44\%) really worrisome data that, in fact, raise the need to contribute to the regulation of these emotional states during competitions. Similarly, although with slight differences, the values of somatic anxiety are presented where it is observed that twenty-one youth baseball players (84\%) moderately experience a lot of physiological signs of anxiety, in this case, the difference with the indicators described above is that the tendency is greater in its moderate presentation, where twelve athletes (48\%) involved with this value are observed.

\section{Attitude Test for Competition (APC)}

Analyzing the first indicator (certainty of the forces-CE) it is observed that only $56 \%$ of athletes are sure of their possibilities, elements that denote fears and dissatisfactions that could be linked to several factors (insufficient physical and psychological preparation, personality characteristics, and inadequate self-assessment, among others). The fact is that, in a group way, baseball, as a collective sport, needs the majority of its players to be objectively sure of their own possibilities. An unfavorable situation is shown in the indicator related to the assessment of the forces of the opponent (NOC) where $84 \%$ of the sample underestimates the real possibilities of their opponents, evidencing with this that, for the most part, they do not perform a deep analysis of each opposing player to have as an important element their weaknesses and strengths by virtue of achieving a better result. Despite what has been stated in the previous parameters, it is encouraging to note that the majority of Santiago youth athletes (96\%) give high significance to the competition 
(GIS), an essential element that mobilizes the collective wishes to participate and comply with the strategies and goals traced for this fundamental event. In another sense, it can be noted that $76 \%$ of baseball players express a high orientation on the opinion of teammates and the coach (OP). This analysis shows that the majority do not have adequate self-esteem, undervalue their position within the team, and limit their independence and creativity when making decisions in the competition.

\section{Pulsometry}

It is emphasized that the plyometric tests were carried out for five months with a weekly frequency of five applications. During training sessions $80 \%$ of the participants in the study tend to maintain their heart rates within the average or normal parameters, with this evaluation prevailing during the stage, this corresponds to the low influence of commonly stressful elements and anxiety generators However, it is evident the different behavior of these values during competitions, $76 \%$ of athletes tend to accelerate their heart rhythms under these circumstances, the athlete, being anxious automatically releases adrenaline, a hormone that can accelerate the rhythm cardiac, this prepares the body to use more oxygen and energy to escape or face the potential danger. Because each individual's body is unique and reacts differently to exercise, the desired heart rate is presented as a range within which it should remain, rather than an exact number. Anxiety can contribute to increased heart rate and blood pressure, so the need to maintain better control of it is emphasized.

\section{Time appreciation test}

There are notable differences between the performance obtained by athletes in performing the test in competitive and training situations. During the first (competitive) circumstances 64\% of baseball players maintain an accelerated performance, this implies that subjective distortions of chronological time occur, in this case, shortening it. This result can occur when athletes feel insecurities, poor control of their emotions, fears and negative thoughts, among other signs of anxious behavior. On the other hand, during training sessions, where the individual usually feels calmer, regardless of the physical load he receives, $76 \%$ manage to maintain the usual performance.

\section{Conclusion}

a) There are significant differences between the manifestations of anxiety, reflected through cognitive, physiological and behavioral indicators, present in usual training conditions and in the competitive field.

b) For a large part of Santiago youth baseball players, the competition is a favorable framework to present anxious behaviors, the most frequent being digestive discomfort, onychophagy, hand sweating, increased heart rate, worries, negative thoughts and difficulties to concentrate, as well as the manifestations of nervousness, disorganized movements and technical tactical errors.

c) $84 \%$ of Santiago athletes who were part of this sample have a high incidence of somatic, cognitive and selfconfidence anxiety.

d) Many of the athletes adjudicate the causes of anxious behaviors to the pressure exerted by the family, the need for social recognition as well as the presence of inadequate management of the coaches through nonconstructive criticism

\section{Conflict of interest statement}

The authors declared that they have no competing interests.

\section{Statement of authorship}

The authors have a responsibility for the conception and design of the study. The authors have approved the final article.

Acknowledgments

Special recognition is made to the editors of the IRJMIS, for supporting us based on the publication of this paper.

Chang, M. O., \& Torres, A. C. M. (2019). Multidimensional diagnosis of competitive anxiety in youth baseball team. International Research Journal of Management, IT and Social Sciences, 6(6), 104-110. https://doi.org/10.21744/irjmis.v6n6.783 


\section{References}

Cisneros, M. (2016). Psychological intervention plan for anger control in baseball pitchers. Master thesis, University of Physical Culture and Sports Sciences Manuel Fajardo, Granma, Cuba.

Compta, R. \& Naples, N. (2015). Active therapy in the emotional states of the baseball team category 13-14 years in Santiago de Cuba. EFDeportes.com, Digital Magazine. Buenos Aires - Year 20 - $\mathrm{N}^{\mathrm{o}} 206$ http://www.efdeportes.com/

García, F. (2001). Emotions as a result of training loads. http://www.efdeportes.com/ Digital Magazine - Buenos Aires $7(41)$.

García, L. (2019). The negative influence of parents in the development process for baseball learning arrangements

Jodra, P. (2002). Anxiety in sports. Arbitrum Retrieved from https://www.researchgate.net/publication/228904490

Milanés, Y. (2015). Generalities of the study of competitive anxiety. Olimpia Magazine, 13(38).

Oliva, A. \& Ochoa, M. (2016). Training program with cognitive-behavioral techniques for the control of precompetitive anxiety. Tesina de Diplomado, Universidad de Oriente, Facultad de Cultura Física Manuel Fajardo, Santiago de Cuba, Cuba.

Ordeñez, V. M. (2003). La ansiedad precompetitiva como indicador de rendimiento en nadadores de siete a diez años de edad. Toma de la base de datos del Centro de Recursos de información para el deporte cubano.

Singh, A., \& Parmar, D. S. (2015). A comparative study of competitive anxiety between basketball and volleyball players. International Research Journal of Management, IT and Social Sciences, 2(1), 1-4.

Sjaifullah, A. (2019). An analysis of EFL students' anxiety factors in speaking. International Research Journal of Engineering, IT \& Scientific Research, 5(3), 43-48. https://doi.org/10.21744/irjeis.v5n3.655

Suárez, H. (2016). Estrategia de intervención psicológica para la concentración de la atención en lanzadores de béisbol social en Granma. Tesis de maestría, Universidad de Ciencias de Cultura Física y el Deporte Manuel Fajardo, Granma, Cuba.

Wanton-Prince, E., \& Sánchez-López, J. N. (2013). Método para el desarrollo de la fuerza explosiva en lanzadores de béisbol. Arrancada, 13(24), 1-9.

Williams, S. (1991). Psicología aplicada al deporte. Madrid, Biblioteca Nueva 